\title{
Efficacy of growth hormone in improving the pregnancy rate in poor responders in ART
}

\author{
Nisha E. ${ }^{1}$, Sunitha H. B. ${ }^{2 *}$, Vidya V. Bhat ${ }^{3}$, K. M. Guddy ${ }^{3}$ \\ ${ }^{1}$ Department of Obstetrics and Gynecology, Srinivasan Hospital, Thuraiyur, Tamil Nadu, India \\ ${ }^{2}$ Department of Obstetrics and Gynecology, Gadag Institute of Medical Sciences. Gadag, Karnataka, India \\ ${ }^{3}$ Department of Obstetrics and Gynecology, Radhakrishna Multispeciality Hospital, Bengaluru, Karnataka, India
}

Received: 02 June 2017

Accepted: 09 June 2017

*Correspondence:

Dr. Sunitha H. B.,

E-mail: suni.hb14obg@gmail.com

Copyright: ( ) the author(s), publisher and licensee Medip Academy. This is an open-access article distributed under the terms of the Creative Commons Attribution Non-Commercial License, which permits unrestricted non-commercial use, distribution, and reproduction in any medium, provided the original work is properly cited.

\section{ABSTRACT}

Background: Poor responders impose a great challenge to ART clinicians. Research to improve their pregnancy rate is going on. This study was conducted to analyze the effect of growth hormone in poor responders in ART.

Methods: This study was done from January 2015 to December 2015. It was a retrospective, single centre, cohort study in which 36 poor responders were selected and allotted into group A (18) with growth hormone and group B (18) without growth hormone. High dose of gonadotrophins was used for ovarian stimulation and antagonist protocol was followed in all patients. Group A received $4 \mathrm{IU}$ of growth hormone along with usual treatment from day 2 till ovulation trigger with HCG injection, group B usual protocol.

Results: Statistical analysis was done with independent $T$ test, and $\mathrm{p}$ value $<0.05$ was considered significant. Higher number of mature oocytes and pregnancy rates were observed in growth hormone group. Number of MII oocytes was 5.8 , on an average in group A and 3.7 in group B, the difference was statistically significant (p 0.0000001). Clinical pregnancy rates were $27.7 \%$ in group A and $16.6 \%$ in group B, statistical significance (p 0.02).

Conclusions: Addition of growth hormone shows increase in number of oocytes retrieved and pregnancy rates in poor responders in ART patients.

Keywords: ART, Growth hormone, Poor responders, Pregnancy rate with growth hormone

\section{INTRODUCTION}

The success of IVF treatment is highly dependent upon the ovarian reserve and the number of oocytes retrieved. The incidence of poor responders has been analyzed as 9 $24 \%{ }^{1}$

Many factors have been stated to be responsible for poor response like age, BMI, previous ovarian surgery, family history, rarely unknown cause. ${ }^{2}$ There was no uniform criteria to define poor responders previously, but ESHRE 2011 Bologna criteria defines poor responders as: ${ }^{3}$

- Advanced maternal age $>40$ years
- Previous poor ovarian response ( $<3$ oocyte cumulus complex retrieved)

- Abnormal ovarian reserve testing

Two out of three criteria should be positive to define poor responders.

Various measures have been tried to improve poor response- like changing protocol- micro flare protocol, antagonist protocol, increasing the dose of gonadotrophins, addition of androgens in the form of DHEA (dehydroepiandrosterone sulphate) and testosterone gel, addition of recombinant LH, and adjuvant growth hormones. ${ }^{4}$ This study aims at analyzing 
the pregnancy outcomes with addition of growth hormone.

\section{METHODS}

This study was a retrospective, single centre, interventional study, Conducted from January 2015 to december 2015. Total of 36 poor responders were taken, 18 patients were included in each arm, group A with growth hormone, and group B without growth hormone. Informed consent was obtained for the study.

In both the group from day 2 of menstrual cycle, recombinant FSH (rFSH) 300-450 IU was started according to the age, BMI, $\mathrm{AMH}, \mathrm{AFC}$, and prior response. Patient reviewed on day 8 to see the response with E2, LH, TVS monitoring of the follicular size. Depending on the response, rFSH dose was adjusted, with addition of HMG at times. When the lead follicle reached $14 \mathrm{~mm}$ then $\mathrm{GnRH}$ antagonist cetrorelix $0.25 \mathrm{mg}$ was started, and continued till HCG injection. When 2-3 lead follicles reached $17-18 \mathrm{~mm}$ injection $\mathrm{rHCG} 250-500$ micro grams was given subcutaneous.

In group A injection human growth hormone 4 IU was included in the protocol described above from day 2 of the cycle when stimulation begins till HCG. Group B nothing was added to regular protocol. 34-36 hours after HCG injection, ovum pick up was done with cooks single lumen catheter, oocyte cumulus complex incubated for 24 hours, then denudation done followed by ICSI. Embryo assessed and transfer was done on day 3/day 5 and excess embryos frozen. Luteal support was given with natural micronized progesterone by vaginal route. The statistical analysis was done by independent $t$ test.

\section{Inclusion criteria}

- Age $>35$

- Previous poor ovarian response (<3 oocyte cumulus complex)

- Poor ovarian reserve $\mathrm{AMH}<1 / \mathrm{AFC}<5$

- Patient giving consent for the study.

\section{Exclusion criteria}

- Patient having contraindication for gonadotrophins/ growth hormone

- Patient with DM or at risk with GDM

- Patient with malignancy or prior history of malignancy

- Poorly controlled thyroid disorder

- Normo responders and hyper-responders.

\section{RESULTS}

The mean age of both group A and group B was comparable-37.1 and 37.3 respectively. Causes for infertility factors evaluated in detail prior to initiation of treatment were also similar in both groups with no statistical significance. Ovulatory dysfunction was the most common factor for infertility in both groups.

Table 1: Age distribution and causes of infertility.

\begin{tabular}{|lll|}
\hline Factors & Group A & Group B \\
\hline Age (mean) & 37.1 years & 37.3 years \\
\hline Type of infertility & & \\
\hline Tubal & 2 & 1 \\
\hline Fibroid & 1 & 2 \\
\hline Endometriosis & 1 & 2 \\
\hline Ovulatory dysfunction & 6 & 5 \\
\hline Male & 2 & 2 \\
\hline Multiple & 4 & 3 \\
\hline Unexplained & 2 & 3 \\
\hline
\end{tabular}

Number of mature oocytes retrieved was significantly higher in group A (5.8) compared to group B (3.7). p $(<0.0000001)$.

Table 2: Outcome of the study.

\begin{tabular}{|llll|}
\hline & Group A & Group B & P value \\
\hline $\begin{array}{l}\text { Average no of } \\
\text { oocytes } \\
\text { retrieved }\end{array}$ & 5.8 & 3.7 & $<0.0000001$ \\
\hline Fertilization rate & $76.1 \%$ & $70.1 \%$ & NS \\
\hline $\begin{array}{l}\text { No of embryos } \\
\text { transferred }\end{array}$ & $2-3$ & $1-3$ & NS \\
\hline $\begin{array}{l}\text { Clinical } \\
\text { pregnancy rate }\end{array}$ & $27.7 \%$ & $16.6 \%$ & 0.02 \\
\hline
\end{tabular}

Fertilization rate were not statistically significant between the two groups $(76.1 \%$ and $70.1 \%)$. The number embryo transfer done was 2-3 in group A and 1-3 in group B.

The most significant aspect was the clinical pregnancy rate of $27.7 \%$ in group $A$ and $16.6 \%$ in group B which was statistically significant (p 0.02).

\section{DISCUSSION}

Human growth hormone is a hormone that raises blood sugar, free fatty acid and insulin like growth factor (IGF1), which stimulates production of proteins. Growth hormone as medication is best known for its use in shortstatured children. ${ }^{5}$

The action of growth hormone on reproduction has been studied in animal and human models. It has been shown that $\mathrm{GH}$ is important in early follicular recruitment, subsequent follicular growth, oocyte maturation, estrogen production. ${ }^{6} \mathrm{GH}$ modulates FSH by up regulating IGF-1. The activities of growth hormone are mediated through IGF-1. ${ }^{7}$ Growth hormone has shown to increase intra uterine IGF-1 levels. ${ }^{8}$

The addition of IGF-1 to gonadotrophins in vitro culture of granulose cells have shown increased gonadotrophin 
action by several mechanisms like augmentation of aromatase activity, progesterone production, 17 betaestradiol production and luteinizing hormone receptor formation. ${ }^{9}$

Several other studies have shown the beneficial effect of growth hormone on poor responders. Schoolcraft in 1997 showed and improved response of ovarian stimulation with addition of growth hormone to micro flare protocol on 32 patients. ${ }^{10}$ Koibianakis et al, did a meta-analysis to prove the role of $\mathrm{GH}$ in poor responders showing increase in live birth rate to be $17 \%$ with addition of GH. ${ }^{11}$ Hazout et al, observed improved response in 245 poor responders. ${ }^{12}$

Yovich JL et al, showed a study on 159 women and 2 different doses of growth hormone 10IU was included, in one group 7,14, 21 days preceding stimulation and day 2 of stimulation and other group with day 2, 6, 8, 10 of stimulation, showing improved response with growth hormone. ${ }^{13}$

No consensus has been reached regarding the ideal dose of $\mathrm{GH}$, timing and how long to give. Finally, Cochrane data has come on growth hormone which concludes saying the use of growth hormone significantly improves the live birth rate although the exact subgroup of poor responders who will benefit from growth hormone is yet to be identified. ${ }^{14}$

Headache visual disturbances nausea vomiting, joint swelling is few of the side effects of growth hormone observed in some of the studies, but in our study no patient had any significant side effects. ${ }^{15}$

\section{CONCLUSION}

Addition of growth hormone has shown to be increasing pregnancy outcomes in poor responders.

Till no particular protocol or treatment is given by standard guidelines for poor responders to be superior than others, addition of growth hormones appears to be a reasonable alternative with whatever protocol one is following.

Funding: No funding sources

Conflict of interest: None declared

Ethical approval: The study was approved by the Institutional Ethics Committee

\section{REFERENCES}

1. Ben-Rafael Z, Bider D, Dan U, Zolti M, Levran D, and Mashiach S. Combined gonadotropin releasing hormone agonist/human menopausal gonadotropin therapy (GnRHa/hMG) in normal, high, and poor responders to hMG. J In Vitro Fertiliz Embryo Transfer. 1991;8(1):33-6.
2. Jenkins JM, Davies DW, Devonport H, Anthony FW, Gadd SC, Watson RH et al. Comparison of 'poor' responders with 'good'responders using a standard buserelin/human menopausal gonadotrophin regime for in-vitro fertilization. Human Reprod. 1991;6(7):918-21.

3. Younis JS. The Bologna criteria for poor ovarian response; has the job been accomplished? Human Reprod. 2012;27(6):1874-5.

4. Surrey ES, Bower J, Hill DM, Ramsey J, Surrey MW. Clinical and endocrine effects of a microdose $\mathrm{GnRH}$ agonist flare regimen administered to poor responders who are undergoing in vitro fertilization. Fertil Steril. 1998;69(3):419-24.

5. Homburg R, Eshel A, Abdalla HI, Jacobs HS. Growth hormone facilitates ovulation induction by gonadotrophins. Clin Endocrinol. 1988;29(1):113-8.

6. Hsu DJ, Hammond JM. Concomitant effects of growth hormoneon secretion of insulin-like growth factor I and progesterone bycultured porcine granulosa cells. Endocrinology. 1987;121(4):1343-8.

7. Yoshimura Y, AndoM, Nagamatsu S, Iwashita M, Adachi T, Sueoka K. Effects of insulin-like growth factor-I on follicle growth, oocytematuration, and ovarian steroidogenesis and plasminogen activatoractivity in the rabbit. Biol Reprod. 1996;55(1):152-60.

8. Mason HD, Martikainen H, Beard RW, Anyaoku V, Franks S.Direct gonadotrophic effect of growth hormone on oestradiolproduction by human granulosa cell in vitro. J Endocrinol. 1990;126:R1$\mathrm{R} 2$.

9. Blumenfeld Z, Amit T. The role of growth hormone (GH), GH receptor and GH-binding protein in reproduction and ovulation induction. J Pediatr Endocrinol Metabol. 1996;9:145-62.

10. Schoolcraft W, Schlenker T, Gee M, Stevens J, Wagley L. Improved controlled ovarian hyperstimulation in poor responder in vitro fertilization patients with a micro dose folliclestimulating hormoneflare, growth hormone protocol. Fertil Steril. 1997;67(1):93-7.

11. Kolibianakis EM, Venetis CA, Diedrich K, Tarlatzis $\mathrm{BC}$, Griesinger G. Addition of growth hormone togonadotrophins in ovarian stimulation of poor responders treated by in-vitro fertilization: a systematic review and metaanalysis. Human Reprod Update. 2009;15(6):613-22.

12. Hazout A, Junca AM. A pilot, prospective, randomised, doubleblind, placebo-controlled study to compare protocols for ovarianstimulation with $\mathrm{r}$ hRSH (Gonal-F) combined with two differentdoses of $\mathrm{r}$-hGH or placebo in patients with oocyte dysmorphy undergoing ICSI. Human Reprod. 2003;18(Supplement 1):299-12.

13. Yovich JL, Stanger JD. Growth hormone supplementation improves implantation and pregnancy productivity rates for poor-prognosis patients undertaking IVF. 2010;21(1):37-49. 
14. Growth harmone for invitro fertilization. The cochrane library. Cochrane Database Sys Rev. 2010:1.

15. Dor J, Seidman DS, Amudai E, Bider D, Levran D, Mashiach S. Adjuvant growth hormone therapy in poor responders to in-vitro fertilization: a prospective randomized placebo-controlled double-blind study. Human Reprod. 1995;10(1):40-3.
Cite this article as: Nisha E, Sunitha HB, Bhat VV, Guddy KM. Efficacy of growth hormone in improving the pregnancy rate in poor responders in ART. Int J Reprod Contracept Obstet Gynecol 2017;6:2883-6. 